\title{
DYNAMIC ANALYSIS OF A REINFORCED CONCRETE HORIZONTAL CURVED BEAM USING SOFTWARE
}

\author{
Kulkarni D. B ${ }^{1}$, Ingawale N. $S^{2}$ \\ ${ }^{1}$ Asso. Professor, Department of Civil Engineering, Rajarambapu Institute of Technology, Rajaramnagar \\ ${ }^{2}$ M. Tech. Scholar, Department of Civil Engineering, Rajarambapu Institute of Technology, Rajaramnagar
}

\begin{abstract}
Dynamic analysis of a reinforced concrete beam bridge, horizontally curved in plan is done using a finite element software. The support conditions considered are simple supports. Dynamic loading in the form of moving vehicular load is taken into account for the purpose of analysis. IRC Class AA type of vehicle is simulated on two lanes on the beam of span 31m, having a box type cross-section. A parametric study is done varying the radius of curvature of the beam from $50 \mathrm{~m}$ to $250 \mathrm{~m}$ with the interval of 50 $m$ to check the behavior of the beam. Various responses of the beam like bending moment, shear force, torsional moment and deflection are calculated. The influence of a non-dimensional parameter L/R i.e. ratio of length of the beam to radius of curvature of the beam is verified for the responses of the beam. From the results, it has been found that the responses i.e. the bending moment, shear force, torsional moment and deflection of the beam decrease as the radius of curvature of the beam in increased. Also, the responses of the beam increase as the L/R ratio is increased.
\end{abstract}

Keywords: Dynamic analysis, horizontally curved beam, finite element, moving vehicular moving load, Simply Supported, Box type, parametric study, L/R ratio

\section{INTRODUCTION}

Box type bridge beams, have gained much importance in various areas of civil engineering because of their serviceability, stability, structural competence and construction economy. Reinforced concrete curved beams find their applications in number of areas like highway intersections, elevated freeways, curved bridges etc. The analytical analysis of these is complex due to their three dimensional behaviours due to the fact that these may be subjected to moving loads, thrust loads, impact loads along with bending moments, shear forces and torsional moments [11]. Thus, sometimes larger depths are needed to resist these high loads. Thus, there should be a proper and special care taken on order to analyze and design such structures which include the effect of all above parameters. Yang and $\mathrm{Wu}$ [17] derived the analytical solutions for curved horizontal beam subjected to horizontal and vertical moving loads. The authors considered both types of moving loads, namely single and an equidistant series. Nallasivam et al. [12] analyzed the impact using dynamics of bridge-vehicle couple on curved box-girder due to vehicle moving through bridge deck considering the influence of the centrifugal forces due to vehicle moving on curved bridge. Awall et al. [1] studied and analyzed extended three-dimensional finite element interaction, parametrically modelling the bridge in detailed with solid and shell elements for concrete deck and steel members, respectively by simulation of a threedimensional nonlinear model consisting of several lumped masses connected by rigid beams and supported by spring dampers. Sarode and Vesmawala [15] analysed numerous models for curved box girders using LUSAS FEA software for different parameters such as span lengths, radii and loadings and the flexural and torsional behavior. However, until now no significant research has been put forth concerning reinforced concrete horizontally curved beams.

\section{MODELLING OF BOX GIRDER BEAM FOR PARAMETRIC STUDY}

The geometry of Box Beam Bridge considered in the present work is based on the report of the Bangalore Metro Rail Corporation (BMRC) Limited, $31 \mathrm{~m}$ in span. The crosssection consists of a single cell box beam bridge, having total with of $9.6 \mathrm{~m}$ and total depth of $2.31 \mathrm{~m}$. The overall thickness of the beam is $381 \mathrm{~mm}$. The details of the cross section considered for this study is given in Figure 1 and various geometric cases considered for this study are presented in Table 1 . The material property considered for the present study is shown in Table 2.

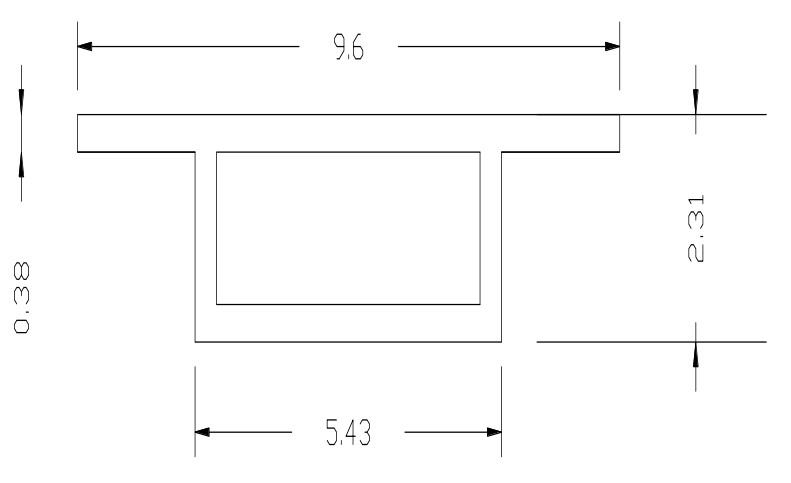

Fig.1 Cross Section of Beam (Dimensions in $\mathrm{m}$ ) 
Table 1: Geometry of Bridges Girders used in Parametric Study

\begin{tabular}{|l|l|}
\hline Radius (m) & Subtended Angle (Degrees) \\
\hline 50 & 35.523 \\
\hline 100 & 17.762 \\
\hline 150 & 11.841 \\
\hline 200 & 8.881 \\
\hline 250 & 7.105 \\
\hline
\end{tabular}

Table 2: Material Properties used for modelling

\begin{tabular}{|l|l|}
\hline Properties of Material & Value \\
\hline Mass per unit volume & $24 \mathrm{kN} / \mathrm{m}^{3}$ \\
\hline Modulus of Elasticity (E) & $32500 \times 103 \mathrm{kN} / \mathrm{m}^{2}$ \\
\hline Shear Modulus (G) & $1.413 \times 107 \mathrm{kN} / \mathrm{m}^{2}$ \\
\hline Poisson's Ratio (v) & 0.15 \\
\hline $\begin{array}{l}\text { Specific Concrete Compressive } \\
\text { Strength (fc') }\end{array}$ & $45000 \mathrm{kN} / \mathrm{m}^{2}$ \\
\hline
\end{tabular}

\section{FINITE ELEMENT MODELLING}

The modelling of box type Beam Bridge is carried out using commercially available finite element software, SAP2000. Shell element is used in this finite element model to discretize the bridge cross section. The bridge is simply supported at both the ends. At each node, it has six degrees of freedom i.e. translations in the nodal $\mathrm{x}, \mathrm{y}$, and $\mathrm{z}$ directions and rotations about the nodal $\mathrm{x}, \mathrm{y}$, and $\mathrm{z}$ axes. A moving load analysis is performed for Live Load of IRC 6 Class AA (Tracked Vehicle) loading on two lanes of $3.658 \mathrm{~m}$ width. The bending moments, shear forces, torsional moments and deflection are calculated.
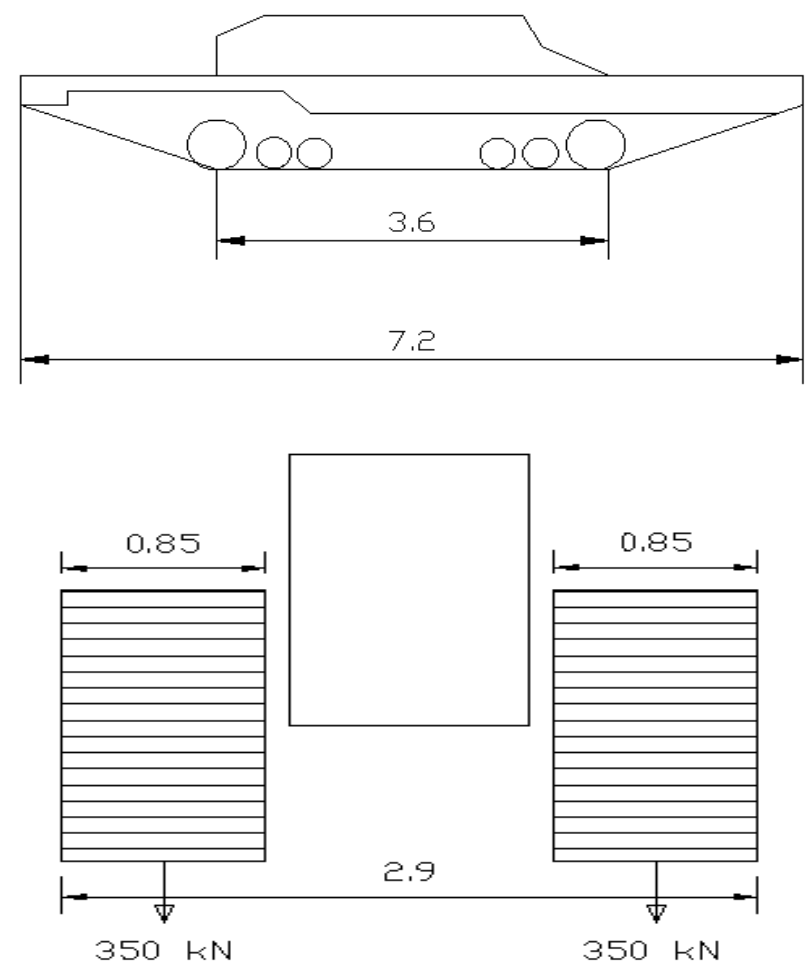

Fig.2 IRC Class AA (Tracked Vehicle) loading (Dimensions in meters)

\section{RESULTS}

Dynamic analysis and a parametric study of single cell box beam bridges curved in plan is carried out. For this purpose, five box girder bridge were modelled with constant span length and varying curvature in Finite Element Software. All the models are subjected to self-weight and moving load of IRC class AA tracked vehicle load.

Table 3: Variation of bending moment

\begin{tabular}{|l|l|}
\hline Radius (m) & BM (kNm) \\
\hline 50 & 6077.395 \\
\hline 100 & 6029.052 \\
\hline 150 & 5973.410 \\
\hline 200 & 5942.301 \\
\hline 250 & 5927.091 \\
\hline
\end{tabular}

Table 4: Variation of shear force

\begin{tabular}{|l|l|}
\hline Radius (m) & Shear Force $(\mathbf{k N})$ \\
\hline 50 & 791.884 \\
\hline 100 & 790.117 \\
\hline 150 & 789.165 \\
\hline 200 & 788.868 \\
\hline 250 & 787.965 \\
\hline
\end{tabular}

Table 5: Variation of Torsional Moment

\begin{tabular}{|l|l|}
\hline Radius (m) & Torsional Moment (kNm) \\
\hline 50 & 2027.461 \\
\hline 100 & 1770.261 \\
\hline 150 & 1622.656 \\
\hline 200 & 1475.996 \\
\hline 250 & 1467.398 \\
\hline
\end{tabular}

Table 6: Variation of deflection

\begin{tabular}{|l|l|}
\hline Radius (m) & Deflection $(\mathbf{m m})$ \\
\hline 50 & 116.03 \\
\hline 100 & 104.56 \\
\hline 150 & 95.460 \\
\hline 200 & 87.500 \\
\hline 250 & 85.900 \\
\hline
\end{tabular}

\section{VARIATION OF THE RESPONSES WITH L/R RATIO FOR MOVING LOAD}

A non-dimensional parameter $(\mathrm{L} / \mathrm{R})$ is considered to plot the variation of the maximum responses of the horizontally curved beam bridge. Models are analyzed for different L/R i.e. span length to the radius of curvature of ratio to illustrate the variation of responses of single cell box Beam Bridge i.e. bending moment, shear force, torsional moment and deflection. 
BENDING MOMENT VS L/R RATIO

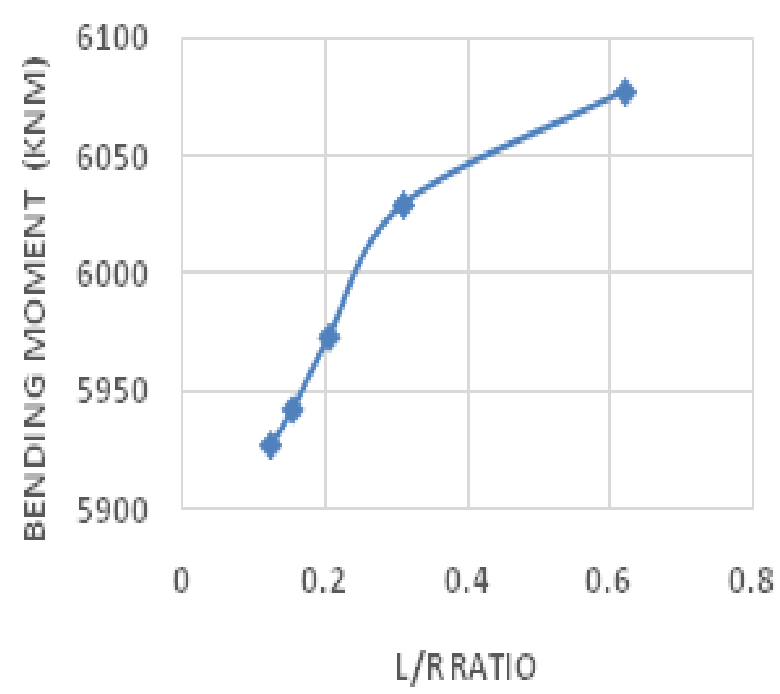

Fig 3: Variation of bending moment with $L / R$ ratio

\section{SHEAR FORCE VS L/R RATIO}

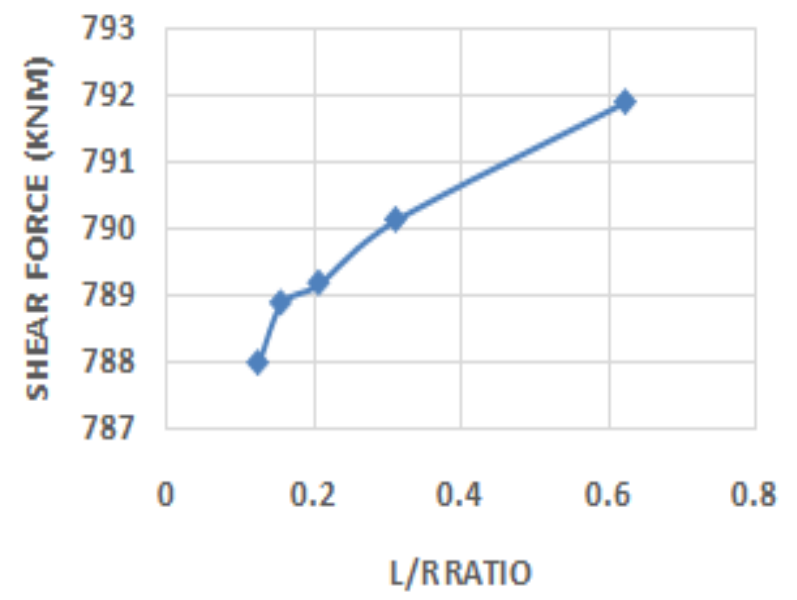

Fig 4: Variation of shear force with $\mathrm{L} / \mathrm{R}$ ratio

\section{TORSIONAL MOMENT VSL/RRATIO}

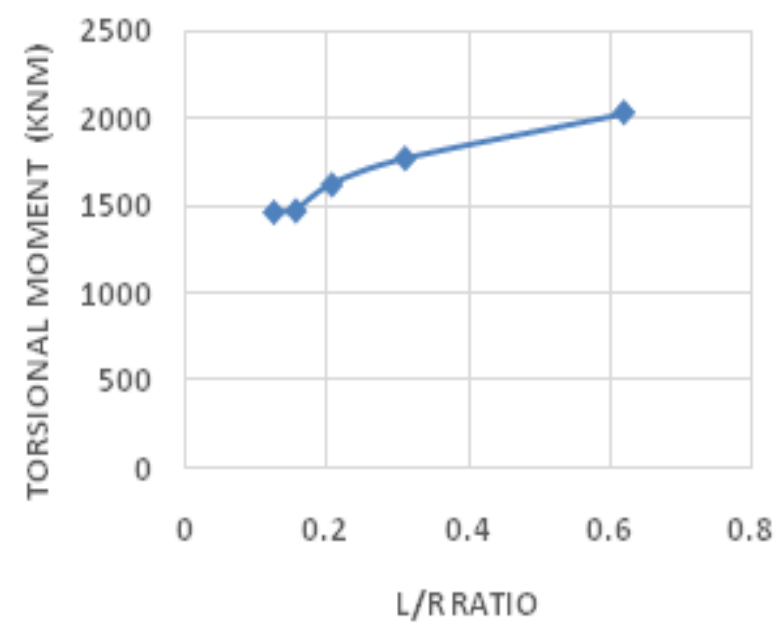

Fig 5: Variation of L/R ratio with torsional moment
DEFLECTION VS L/R RATIO

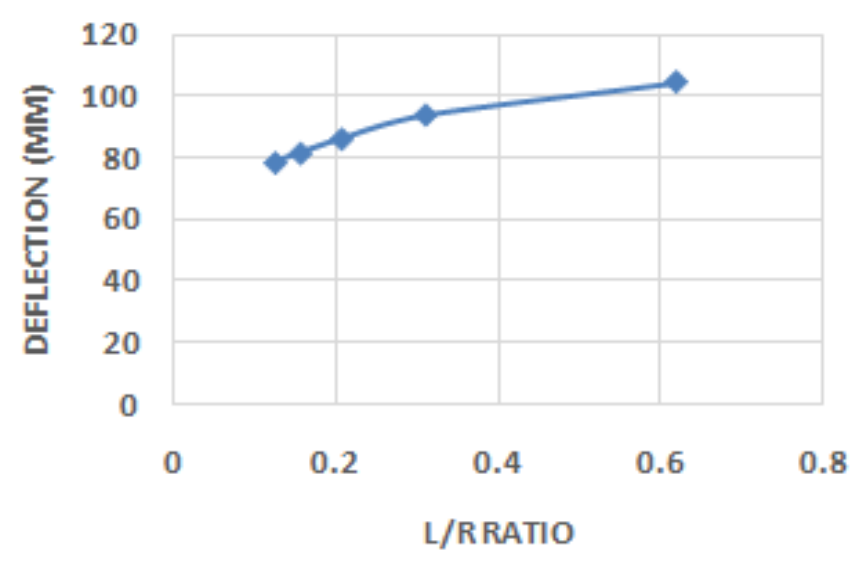

Fig 6: Variation of deflection with $L / R$ ratio

\section{CONCLUSION}

The present study focus on the parametric study of single cell box Beam Bridge curved in plan. For the purpose of the parametric study, five box girder bridge were modelled with constant span length and varying curvature in Finite Element analysis Software. The parameter that was varied was the radius of curvature of the beam bridge. All the models were subjected to self-weight and moving load of IRC class AA tracked vehicle load. A dynamic analysis for dead load and moving load was performed. The response of the box beam bridge i.e. bending moment, shear force, torsional moment and deflection were recorded. From the analysis results, following conclusions were framed; Increasing the radius of curvature from $50 \mathrm{~m}$ to $100 \mathrm{~m}$, the response of the girder shows $10.261 \%$ decrease in the midspan vertical deflection.

Further increasing the radius of curvature upto $150 \mathrm{~m}$, there is $8.308 \%$ decrease in the mid-span deflection of the curved bridge girder.

When the radius of curvature is further increased from 150 $\mathrm{m}$ to $200 \mathrm{~m}$, it shows there is $5.384 \%$ decrease in the midspan vertical deflection.

The Bending moment and shear responses of curved box bridge beam show that there is no significant variation with increase in the radius of curvature of the beam. The responses decreases by less than $1 \%$ to every $50 \mathrm{~m}$ increase in the radius of curvature.

The torsional moment of box beam bridge decrease by $12.686 \%$ when the radius of curvature is increased from 50 $\mathrm{m}$ to $100 \mathrm{~m}$.

Further the torsional moment decrease by $8.338 \%$ and $9.038 \%$ when the radius of curvature is increased to $150 \mathrm{~m}$ and $200 \mathrm{~m}$ respectively.

Increase in the radius of curvature by $50 \mathrm{~m}$ show no significant variation in the torsional moment of the beam bridge. 


\section{REFERENCES}

[1] Awall et al. (2011) Parametric Study on Bridgevehicle Interaction Dynamics of Horizontally Curved Twin I-girder Bridge. 8th International Conference on Structural Dynamics, 4-6 July.

[2] Bradford, M. A., Uy, B. and Pi, Y. L. (2001). Behaviour of unpropped composite girders curved in plan under construction loading. Engineering Structures, (23), 779-789.

[3] Chang, C. C. and Wang, Y. M. (2007). Dynamics and Control of a Moving Mass Traveling on an Initially Curved Beam. Journal of Marine Science and Technology, 15 (4), 273-277.

[4] Fangping, L. and Jianting, Z. (2012). The Deformation Analysis of the Curved Box Girder Bridges under Different Radius. Modern Applied Science. 6 (4), 71-76.

[5] Gupta et al. (2010) Parametric Study on Behavior of Box-Girder Bridges using Finite Element Method, Asian Journal of Civil Engineering, 11 (4), 135-148.

[6] Gentile, C. and Martinez, F. (2004). Dynamic performance of twin curved cable-stayed bridges. Earthquake Engineering and Structural Dynamics. $33,15-34$.

[7] Hundekar, P. S. and Kulkarni, D. K. (2014). Performance Based Analysis of Bridge Deck for Distinctive Girder Types. International Journal of Engineering Research \& Technology (IJERT), 3 (8), 694-697.

[8] IRC: 6-1966 'Standard Specifications and code of practice for Road Bridges, Section II (Loads and Stresses) Indian National Congress, 1974.

[9] Javid, F., Esmailzadeh, E. and Younesian, D. (2011). An Investigation Into the Vehicle-Curved Bridge Dynamic Interaction. International Journal of Automotive Engineering, 1 (3), 235-243.

[10] Kefei, L., Weining, L., Valeri, M., and Longxiang, M. (2012). Analytical Study on the Vibration Response of Curved Track subjected to Moving Load. International Conference on Railway Engineering.

[11] Máca, J. and Valášek, M. (2006). Vibration Control of Bridges under Moving Loads. Slovak Journal of Civil Engineering, 3, 1-4.

[12] Nallasivam, K., Dutta, A. and Talukdar, S. (2007). Dynamic analysis of horizontally curved thin-walled box-girder bridge due to moving vehicle. Journal of Shock and Vibration, 14, 229-248.

[13] Ouchenane, M., Lassoued R. and Ouchenane K. (2009). Vibration Analysis of Bridges Structures under the Influence of Moving Loads. 3rd International Conference on Integrity, Reliability and Failure, Porto/Portugal., 20-24 July.

[14] Pathak, M. (2014). Performance of RCC Box type Superstructure in Curved bridges. International Journal of Scientific \& Engineering, 5(1), 2229-5518.

[15] Sarode, A. B. and Vesmawala, G. R. (2014). Parametric Study of Horizontally Curved Box Girders for Torsional Behavior and Stability. International Refereed Journal of Engineering and Science (IRJES)., 3 (2), 50-55.
[16] Topkaya, et al. (2004). Behaviour of curved steel trapezoidal box-girders during construction. Engineering Structures, (26), 721-733.

[17] Yang, Y. B. and Wu, C. M. (2001). Dynamic Response of a Horizontally Curved Beam subjected to vertical and horizontal moving loads. Journal of Sound and Vibration, 242 (3), 519-537.

[18] Yoo, C. H., Kyungsik K. K. and Byung, H. C. (2005). Research on Horizontally Curved Steel Box Girders. Highway Research Center, Auburn University, Alabama.

[19] Zadeh V. Z and Patnaik A. (2014). Finite element modelling of the dynamic response of a composite reinforced concrete bridge for structural health monitoring. International Journal of Advance Structural Engineering. 6:55, 1-14.

\section{BIOGRAPHIES}

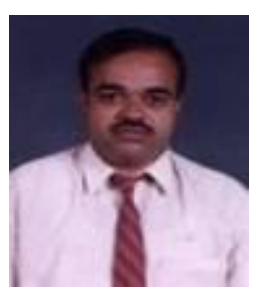

Kulkarni D. B, Assistant Professor, Department of Civil Engineering, Rajarambapu Institute of Technology, Rajaramnagar, Sangli, Maharashtra, India Email:dattatraya.kulkarni@ ritindia.ed $\mathbf{u}$

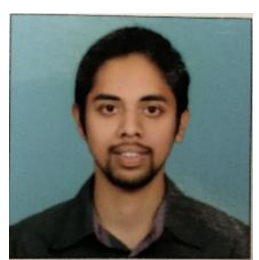

Ingawale N. S, P. G. (Civil-Structure) Scholar, Department of Civil Engineering, Rajarambapu Institute of Technology, Rajaramnagar, Sangli, Maharashtra, India Email:nikkhil13@gmail.com 